\title{
Staphylococcal Pericarditis with Cardiac Tamponade in Children
}

SHYAMAL K. SANYAL, INDER KAUR, VIJAYA HOOJA, MOHINDER K. THAPAR, and $\vec{\circ}$ SARLA VAISHNAVA

From the Paediatric Cardiology Unit, Department of Paediatrics, Safdarjang Hospital, New Delhi, India

Sanyal, Shyamal K., Kaur, Inder, Hooja, Vijaya, Thapar, Mohinder, K., and Vaishnava, Sarla (1970). Archives of Disease in Childhood, 45, 198. Staphylococcal pericarditis with cardiac tamponade in children. Six children with acute staphylococcal pericarditis with cardiac tamponade are presented. In any patient with staphylococcal infection, the sudden onset of dyspnoea, tachycardia, tachypnoea, distended and pulsatile neck veins, hepatomegaly, puffy face and pulsus paradoxus should suggest the diagnosis of pericarditis with acute cardiac tamponade. Prompt drainage by pericardiocentesis or pericardiostomy is essential.

Purulent pericarditis with cardiac tamponade in children, though not a common occurrence, constitutes a potentially lethal disease that warrants prompt recognition and intensive management (Horan, 1957; Nadas and Levy, 1961; Benzing and Kaplan, 1963; Morgan, 1964; and Journal of Pediatrics, 1965). Our purpose is to describe six children with staphylococcal pericarditis who developed cardiac tamponade, and to emphasize the broad clinical spectrum of the disease.

\section{Material and Methods}

This report concerns 6 children, 3 male and 3 female aged 4 to 14 years. The clinical features and mode of presentation are shown in the Table.

Case 1. A 5-year-old boy was admitted with a history of a fall 10 days before, followed by a low grade fever of 9 days' duration and diarrhoea of 2 days' duration. Temperature was $39^{\circ} \mathrm{C}$. There was a positive Kernig's sign and marked neck rigidity. Lumbar puncture showed thick, turbid CSF with low sugar content, polymorphonuclear pleocytosis, and clusters of Gram-positive cocci which, on culture, were identified as Staphylococcus pyogenes sensitive to chloramphenicol. The same organism was isolated from blood culture.

Chloramphenicol, penicillin, and sulphadiazine were started intravenously. 24 hours later, a pericardial rub was heard, shortly followed by signs of acute cardiac tamponade. Chest $x$-ray showed gross cardiomegaly with clear lung fields. He was digitalized. Pericardiocentesis removed $100 \mathrm{ml}$. straw-coloured, thin,

Received 11 August 1969. coagulum-free fluid which, on culture, grew Staph pyogenes but he died soon afterwards.

Comments. This patient presented as staphylococc meningitis. Pericardial rub heralded the onset of suppurative pericarditis with fatal cardiac tamponade

Case 2. A 4-year-old girl was admitted with feve and a painful swelling over the left thigh which developeg following trauma a week before admission.

On admission her temperature was $39^{\circ} \mathrm{C}$. There was an extremely tender, diffuse swelling, $10 \times 10 \mathrm{~cm}$ over the left hip. The skin overlying the swelling was glossy and warm to the touch.

The total white blood cell count was 11,000 , with id shift to the left. Blood culture grew Staph. pyogenes sensitive to spiramycin which was started intravenously? Within the next two weeks the size of the swellin diminished. Coinciding with improvement in the general condition, she suddenly developed an acute episode of cardiac tamponade. She was digitalized and pericardiocentesis removed $300 \mathrm{ml}$. straw-coloured thin coagulum-free fluid which, on culture, grew Staph pyogenes. Following pericardiocentesis she showed improvement, though the swelling over the left thigt: persisted, an $x$-ray confirming osteomyelitis of the femoral shaft. This was treated by immobilization of the lower limb, and she was discharged a few ween later.

Comments. This patient presented with acute osted myelitis. The onset of pericarditis with cardias tamponade coincided with improvement in the generaf condition of the patient.

Case 3. A 6-year-old girl was admitted moribun with a history of fever of 2 weeks' duration and progresi sive dyspnoea of 4 days' duration. 
TABLE

Clinical Data of Six Cases of Staphylococcal Pericarditis

\begin{tabular}{|c|c|c|c|c|c|c|c|c|c|c|c|}
\hline \multirow[b]{2}{*}{$\begin{array}{l}\text { Case } \\
\text { No. }\end{array}$} & \multirow[b]{2}{*}{$\begin{array}{l}\text { Age } \\
\text { (yr.) }\end{array}$} & \multirow[b]{2}{*}{ Sex } & \multirow[b]{2}{*}{$\begin{array}{l}\text { Diagnosis } \\
\text { on } \\
\text { Admission }\end{array}$} & \multicolumn{4}{|c|}{$\begin{array}{l}\text { Signs of Pericardial } \\
\text { Involvement }\end{array}$} & \multirow[b]{2}{*}{$\begin{array}{l}\text { Staphylococcus } \\
\text { Isolation } \\
\text { Culture }\end{array}$} & \multirow[b]{2}{*}{ ECG } & \multirow[b]{2}{*}{$X$-ray } & \multirow[b]{2}{*}{ Outcome } \\
\hline & & & & 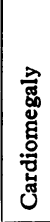 & 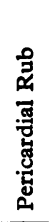 & 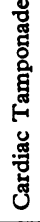 & 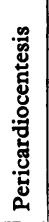 & & & & \\
\hline 1 & 5 & $\mathbf{M}$ & Meningitis & + & + & + & + & $\begin{array}{l}\text { Blood, CSF, and } \\
\text { pericardial fluid }\end{array}$ & 一 & $\begin{array}{l}\text { Cardiomegaly, } \\
\text { clear lung } \\
\text { fields }\end{array}$ & Fatal \\
\hline 2 & 4 & F & Osteomyelitis & + & - & + & + & $\begin{array}{l}\text { Blood and pericardial } \\
\text { fluid }\end{array}$ & $\begin{array}{c}\text { ST segment } \\
\text { elevation }\end{array}$ & $\begin{array}{l}\text { Cardiomegaly, } \\
\text { clear lung } \\
\text { fields }\end{array}$ & Recovered \\
\hline 3 & 6 & $\mathbf{F}$ & $\begin{array}{c}\text { Pericardial } \\
\text { effusion }\end{array}$ & + & - & + & + & $\begin{array}{l}\text { Blood and pericardial } \\
\text { fluid }\end{array}$ & - & $\begin{array}{l}\text { Cardiomegaly, } \\
\text { clear lung } \\
\text { fields }\end{array}$ & Fatal \\
\hline 4 & 12 & $\mathbf{F}$ & $\begin{array}{l}\text { Acute } \\
\text { rheumatic } \\
\text { fever }\end{array}$ & + & + & + & + & $\begin{array}{l}\text { Blood, pericardial } \\
\text { fluid, and skin pustule }\end{array}$ & $\begin{array}{l}\text { ST segment } \\
\text { elevation }\end{array}$ & $\begin{array}{l}\text { Cardiomegaly, } \\
\text { clear lung } \\
\text { fields }\end{array}$ & Recovered \\
\hline 5 & 4 & $\mathbf{M}$ & $\begin{array}{c}\text { Pericardial } \\
\text { effusion }\end{array}$ & + & - & + & + & $\begin{array}{l}\text { Blood and pericardial } \\
\text { fluid }\end{array}$ & 一 & & Fatal \\
\hline 6 & 12 & $\mathbf{M}$ & Intussusception & + & + & + & + & $\begin{array}{l}\text { Blood and pericardial } \\
\text { fluid }\end{array}$ & $\begin{array}{c}\text { ST elevation } \\
\text { T wave } \\
\text { inversion }\end{array}$ & $\begin{array}{l}\text { Cardiomegaly, } \\
\text { clear lung } \\
\text { fields }\end{array}$ & Fatal \\
\hline
\end{tabular}

She was critically ill, with restlessness, air hunger, peripheral collapse, and signs of acute cardiac tamponade. Oxygen, digitalis, and diuretics were given. Pericardiocentesis yielded $300 \mathrm{ml}$. strawcoloured, thin coagulum-free fluid which on culture grew Staph. pyogenes. Within half an hour of admission, she died.

Comments. This patient presented as a case of acute cardiac tamponade with suppurative pericarditis that terminated fatally.

Case 4. A 12-year-old girl was admitted with a history of limp and a tender ankle swelling of two days' duration. There was a tender, swollen, and hot left ankle. Haemoglobin, total and differential white blood cell count, urine, chest $x$-ray, and ECG were normal.

A presumptive diagnosis of acute rheumatic fever was made and aspirin and benzathine penicillin ( $1 \cdot 2$ mega units), given. Within 72 hours, however, the patient became more toxic and started running a high fever up to $39^{\circ} \mathrm{C}$. Several of the joints, including the left sternoclavicular, became inflamed and extremely tender. Erythematous blotchy areas appeared over the extremities and a violaceous rash, with a butterfly distribution, over the face. A pericardial rub was heard. A diagnosis of collagen disorder was entertained and prednisone was added to the regimen. Within 24 hours she became more toxic and broke out into pustules scattered all over the body. LE cell phenomenon was negative. Blood cultures and the pus from skin pustules grew Staph. pyogenes sensitive to penicillin which was started intravenously along with erythromycin.

A week later she developed an acute episode of cardiac tamponade. Chest $x$-ray showed gross cardiomegaly with clear lung fields. Three similar episodes occurred within the following two weeks, each occasion necessitating pericardiocentesis, with removal of $300-400 \mathrm{ml}$. fluid which grew Staph. pyogenes sensitive only to spiramycin. After an initial improvement, she had several febrile episodes over the next few weeks. The last episode was associated with swelling of the ankle joint, which on aspiration yielded pus that grew Staph. pyogenes sensitive to spiramycin to which she responded very well. During a follow-up period of six months, there was a great improvement in her general condition. Chest $x$-ray showed a marked decrease in heart size. Repeated blood and urine cultures were sterile.

Comments. This patient shows the recurrent nature of the cardiac tamponade and the prolonged need for proper antibiotics to eradicate the underlying infective process which may, clinically, mimic acute rheumatic fever or collagen disorder.

Case 5. A 6-year-old girl was admitted moribund, with a history of fever of 1 week's duration and progressive dyspnoea of 3 days' duration. She was critically ill, in respiratory distress, with signs of acute cardiac tamponade. Pericardiocentesis yielded $470 \mathrm{ml}$. fluid which on culture grew Staph. pyogenes. 
Comments. This case presented as pericardial effusion with acute cardiac tamponade terminating fatally.

Case 6. A 12-year-old boy was admitted with a history of intermittent abdominal pain of two days' duration before admission. Physical examination suggested the diagnosis of intussusception and laparotomy confirmed an ileo-ileal intussusception. The diseased segment was resected and an end-to-end anastomosis was made.

A week later he developed fever, tachycardia, and pericardial rub. Blood cultures grew Staph. pyogenes, sensitive to penicillin which was given intravenously 10-12 mega units per 24 hours. In the following weeks he had four episodes of acute cardiac tamponade and multiple abscesses all over the body. Pericardiocentesis was done on each occasion and abscesses were drained. Pus from the abscesses and pericardial fluid grew Staph. pyogenes which was now resistant to penicillin, but sensitive to chloramphenicol and kanamycin. $\mathrm{He}$ was digitalized and the latter two antibiotics were started. After a few days the patient had a fifth episode of cardiac tamponade. Pericardiocentesis was followed by cardiac arrest which did not respond to resuscitative measures.

Comments. This patient developed suppurative pericarditis from staphylococcal septicaemia following abdominal surgery. He had recurrent episodes of acute cardiac tamponade, one of them terminating fatally.

\section{Discussion}

The clinical spectrum displayed by our patients indicates the protean nature of staphylococcal infection involving pericarditis with acute cardiac tamponade. The various modes of presentation included purulent meningitis, acute osteomyelitis, congestive heart failure with cardiac tamponade, acute rheumatic fever, and septicaemia following laparotomy.

During the course of the illness, a sudden onset of dyspnoea with puffy face, distended and pulsatile neck veins, cardiomegaly with muffled heart sounds, and hepatomegaly, strongly suggested pericardial involvement. Paradoxically, in two patients, these acute cardiac signs coincided with control of the septicaemia and improvement in the general condition. Similar observations have been made by others (Folger, 1966; Kaur et al., 1968). In the absence of a pericardial rub it may be difficult to differentiate pericardial effusion from myocarditis: with dilatation of the heart. Rapid development of cardiac enlargement, muffled heart sound $\overrightarrow{\bar{s}}$ globular shape of the heart on $x$-ray, and ECE changes such as ST segment elevation and T wave inversion may be present in both. $X$-rays showin a large cardiac silhouette without passive congestiom of the lung field, as seen in our patients, provide perhaps, the best means of differentiating these two conditions (Nadas and Levy, 1961).

Pulsus paradoxus exceeding $20 \mathrm{~mm}$. $\mathrm{Hg}$, and pulsatile and distended jugular veins in a patierfy with pericarditis with effusion, are highly suggestive of cardiac tamponade. This constitutes a medica्वे emergency requiring immediate drainage of the pericardial sac by aspiration or surgically. 16 aspiration is accomplished easily and with adequate relief of tamponade, and if the aspirated material is thin and coagulum-free, pericardiocentesis may be adequate. If, however, the aspirated fluid is thick or is aspirated with difficulty, pericardiostomy may be preferable.

We wish to thank Dr. P. P. Goel, Medical Superinter $\overrightarrow{0}$ dent, Safdarjang Hospital, New Delhi, for allowing us to use this material, Dr. Shanti Ghosh, Head of the Department of Paediatrics, for critical review of the manuscript, and Dr. S. K. Bhargava and other colleagues for referring cases included in this report.

\section{REFERENCES}

Benzing, G., III, and Kaplan, S. (1963). Purulent pericarditio American fournal of Diseases of Children, 106, 289.

Folger, G. M., Jr. (1966). Suppurative pericarditis. Review $\overline{\bar{F}}$ the problem plus observations on two patients. Clinical Pediatrics, 5, 225.

Horan, J. M. (1957). Acute staphylococcal pericarditis. Pediatric $19,36$.

Fournal of Pediatrics (1965). Clinical Pathological Conferenge (subacute pleuromediastinal pericarditis). The Children⿳⺈
Hospital Medical Center, Boston. 66, 804.

Kaur, I., Hooja, V., Bajaj, S., Vaishnava, S., and Sanyal, S. Rं (1968). Staphylococcal pericarditis with recurrent cardiax. tamponade in an adolescent. Archives Child Health, 10, 97. ¿)

Morgan, J. (1964). Pericardial tamponade: a complication of staphylococcal pericarditis. Canadian Medical Association fournal, 80, 1082.

Nadas, A. S., and Levy, J. M. (1961). Pericarditis in childre American fournal of Cardiology, 7, 109.

Correspondence to Dr. Shyamal K. Sanyal, Paediatrie Cardiologist, X-40/A (First Floor), Green Park, Nef Delhi-16, India. 